\title{
MODELO PARA AVALIAÇÃO DO DESEMPENHO DO SISTEMA DE GESTÃO PARA RESÍDUOS, COM BASE EM SOLUÇÕES PROPOSTAS PARA O CASO DE JOÃO PESSOA - PB
}

\author{
Alexsandra Rocha Meira \\ Doutora em Engenharia de Produção pela Universidade Federal de Santa Catarina, \\ professora e pesquisadora do Centro Federal de Educação Tecnológica da Paraíba, com \\ atuação na área de construção civil. E-mail: alexrmeira@uol.com.br \\ Nelma Mirian Chagas de Araújo \\ Doutora em Engenharia de Produção pela Universidade Federal da Paraíba, professora e \\ pesquisadora do Centro Federal de Educação Tecnológica da Paraíba, com atuação na área \\ de construção civil. E-mail: nelma@jpa.neoline.com.br

\section{Claudia Coutinho Nóbrega} \\ Doutora em Recursos Naturais pela Universidade Federal da Paraíba, professora e \\ pesquisadora do Departamento de Engenharia Civil da Universidade Federal da Paraíba. \\ E-mail: claudiacn@uol.com.br

\section{Gibson Rocha Meira} \\ Doutor em Engenharia Civil pela Universidade Federal de Santa Catarina, professor e \\ pesquisador do Centro Federal de Educação Tecnológica da Paraíba, com atuação na área \\ de construção civil. E-mail: gibson@jpa.neoline.com.br
}

\section{RESUMO}

A partir de um amplo estudo relativo aos resíduos provenientes da construção civil e tomando como base a Resolução $\mathrm{n}^{\mathrm{0}} 307$ do Conselho Nacional de Meio Ambiente CONAMA, entrevistas realizadas com construtoras da cidade de João Pessoa, empresas coletoras, Sindicato da Indústria da Construção Civil de João Pessoa - Sinduscon-JP e a Autarquia Especial Municipal de Limpeza Urbana - EMLUR (órgão público municipal responsável pela limpeza urbana), os autores elaboraram uma proposta para gestão dos resíduos da construção nessa cidade. Com base nesse trabalho, fundamentado em quatro atividades básicas (reunião inicial, planejamento, implementação e monitoramento), propõe-se nesse artigo um modelo, fundamentado em indicadores capazes de auxiliar na análise do desempenho do sistema de gestão, ponderados em função da importância de cada um deles ao sistema. Pode-se afirmar que tais indicadores são instrumentos essenciais ao monitoramento de sistemas de gestão de resíduos que apresentem características semelhantes.

PALAVRAS-CHAVE: sistema de gestão, desempenho, resíduos sólidos, construção civil. 


\title{
MODEL TO EVALUATE THE PERFORMANCE OF THE MANAGEMENT SYSTEM TO CONSTRUCTION WASTE, BASED ON PROPOSED SOLUTIONS TO JOÃO PESSOA - PB
}

\begin{abstract}
Based on a wide study about construction waste and taking as reference the Resolution $n^{\circ}$. 307 from the CONAMA, the interviews with builders of João Pessoa city, local collecting places, Sinduscon-JP and EMLUR (municipal public organism that is responsible for urban cleaning), the authors elaborated a management proposal for the construction waste of that city. That work was structured in four basic activities (initial meeting, planning, implantation and accompaniment). Based on it, this article proposes a model whose performance indicators as means to analyze the performance of the management system. It can be affirmed that such indicators are essential instruments to the accompaniment of the proposed system.
\end{abstract}

KEYWORDS: management system, performance, construction waste, civil construction. 


\section{MODELO PARA AVALIAÇÃO DO DESEMPENHO DO SISTEMA DE GESTÃO PARA RESÍDUOS, COM BASE EM SOLUÇÕES PROPOSTAS PARA O CASO DE JOÃO PESSOA - PB}

\section{INTRODUÇÃO}

A Construção Civil é uma das indústrias que mais explora recursos naturais e, além disso, é a maior geradora de resíduos. No Brasil, as construções, da forma como são conduzidas, são normalmente ambientes propícios à geração de resíduos. Enquanto em países desenvolvidos a média de resíduos provenientes de novas edificações encontra-se abaixo de $100 \mathrm{~kg} / \mathrm{m}^{2}$, no Brasil esse índice gira em torno de $300 \mathrm{~kg} / \mathrm{m}^{2}$ edificado (MONTEIRO, 2001).

Estimativas indicam que o lixo resultante da construção, manutenção e demolição de casas e edifícios representa aproximadamente $40 \%$ a $60 \%$ do resíduo sólido urbano das grandes cidades. Um estudo realizado em cinco cidades do interior de São Paulo estimou a geração de resíduos de construção e demolição (RCDs) variando entre $54 \%$ e $70 \%$ dos resíduos sólidos urbanos (PINTO, 2005)

Diante dessa significativa parcela de entulhos gerada pela Construção Civil e dos impactos ambientais, sociais e econômicos decorrentes desse entulho produzido e de sua deposição inadequada, constata-se a necessidade de soluções rápidas e eficazes em relação à gestão dos resíduos.

Um ponto de partida nesse sentido foi dado com a elaboração e aplicação da resolução de número 307 do Conselho Nacional do Meio Ambiente - CONAMA - (BRASIL, 2002), a qual busca disciplinar o setor da construção civil de forma a estimular a não geração de resíduos sólidos. A Resolução supracitada estabelece diretrizes, critérios e procedimentos para a gestão dos resíduos da construção civil, orientando as ações necessárias de forma a minimizar os impactos ambientais. Ao todo são catorze artigos, que contemplam desde os objetivos da referida Resolução até os prazos para que as ações contidas na mesma sejam implementadas.

Já se tem conhecimento de algumas iniciativas nesse sentido, a exemplo dos trabalhos que vêm sendo desenvolvidos nos municípios de Guarulhos, Piracicaba, Belo Horizonte e São Paulo. Entretanto, na maioria dos municípios brasileiros, a Resolução n ${ }^{0} 307$ não tem atingido os seus objetivos de forma satisfatória. Em estudo realizado por Araújo et al. (2005a) na cidade de João Pessoa, verificou-se que os principais motivos do não atendimento às disposições da referida Resolução são a falta de conhecimento do próprio documento e a conseqüente falta de comprometimento com sua implementação.

A partir dessa constatação, Araújo et al. (2005b) elaboraram uma proposta de gestão para os RCDs da grande João Pessoa, pautada nas especificidades das empresas construtoras e coletoras locais e do aterro sanitário existente na área metropolitana da cidade. Com base nessa proposta, resumidamente explicitada no item 2 , foram desenvolvidos indicadores de desempenho e um modelo de avaliação do sistema de gestão, sendo ambos alvo do presente trabalho. 


\section{PROPOSTA DE GESTÃO DE RESÍDUOS}

Na proposta elaborada por Araújo et al. (2005b) buscou-se obter uma gestão eficiente e eficaz, ou seja, realizada de modo que as necessidades e os objetivos das pessoas sejam consistentes e complementares aos objetivos da organização a qual estão vinculados.

Inicialmente se previu a realização das seguintes atividades: reunião inaugural com todos os envolvidos no processo (sensibilização); planejamento; implantação e monitoramento. A fase de implantação da proposta foi dividida em quatro etapas, quais sejam:

- Qualificação dos agentes envolvidos na gestão dos resíduos - Deverão ser qualificados os fornecedores de dispositivos e acessórios, as empresas coletoras, as empresas geradoras e os destinatários dos resíduos ou áreas de disposição dos mesmos.

- Gestão no canteiro de obras - A gestão nos canteiros contribui muito para não gerar resíduos, pois possibilita que o canteiro fique mais organizado e mais limpo; haja triagem de resíduos; haja reaproveitamento de resíduos antes de descartá-los; os resíduos sejam quantificados e qualificados. Essa etapa deve ser composta das seguintes ações: organização do canteiro; definição de dispositivos e acessórios; limpeza; estabelecimento do fluxo dos resíduos; estudo das possibilidades de reutilização e reciclagem dos resíduos; formalização de procedimentos (em consonância com procedimentos do sistema da qualidade, caso exista).

- Remoção dos resíduos do canteiro - A coleta dos resíduos e sua remoção do canteiro devem ser efetuadas de modo a conciliar alguns fatores, como a compatibilização, com a forma de acondicionamento final dos resíduos na obra, minimização dos custos de coleta e remoção, possibilidade de valorização dos resíduos e adequação dos equipamentos utilizados para coleta e remoção aos padrões definidos em legislação. Nessa etapa deve-se definir o fluxo dos resíduos e formalizar os procedimentos de remoção dos resíduos para os locais de destinação previamente qualificados.

- Destinação dos resíduos - Nessa etapa devem ser combinados compromisso ambiental e viabilidade econômica. Os fatores determinantes na designação de soluções para a destinação dos resíduos são os seguintes: possibilidade de reutilização ou reciclagem dos resíduos nos próprios canteiros, proximidade dos destinatários para minimizar custos de deslocamentos, conveniência do uso de áreas especializadas para a concentração de pequenos volumes de resíduos, visando a maior eficiência na destinação final. Nesta etapa, também, devem-se formalizar os procedimentos.

Para melhor compreensão, a Figura 1 apresenta a proposta resumida da gestão dos resíduos sólidos. 


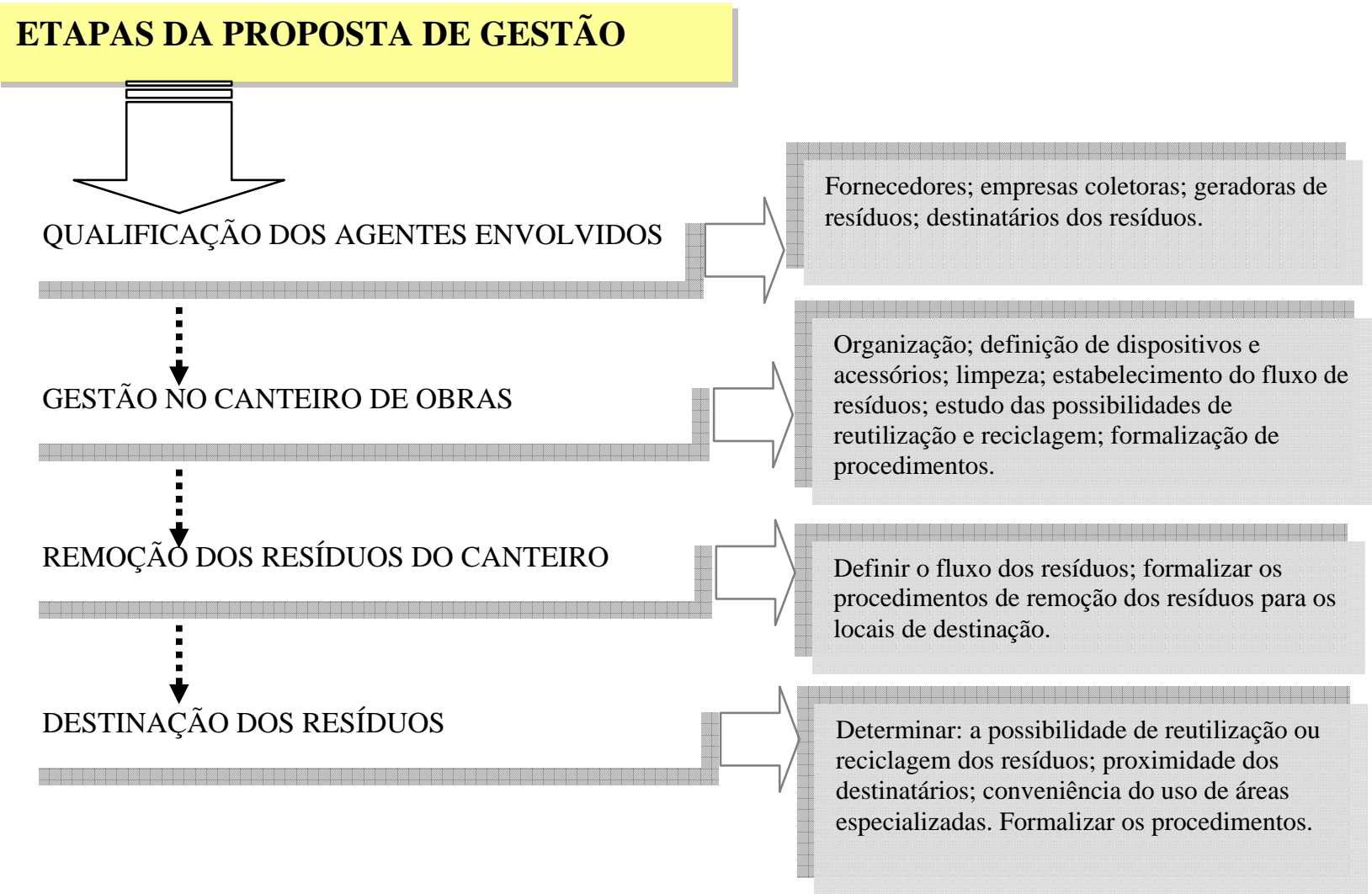

Figura 1: Proposta de gestão dos resíduos oriundos da construção civil.

\section{INDICADORES DE DESEMPENHO}

O sistema de gestão de resíduos proposto ainda não foi implementado, uma vez que as empresas pessoenses ainda não atentaram para a importância e necessidade da gestão dos resíduos.

Entretanto, no momento em que for implementado, quaisquer informações necessárias ao processo de tomada de decisão em relação ao sistema proposto devem ser obtidas por intermédio de medições, as quais podem ser efetuadas através de indicadores.

Os indicadores consistem em expressões quantitativas que representam uma informação gerada, a partir das medições e avaliações de uma estrutura de produção, dos processos que a compõem e/ou dos produtos resultantes. Assim sendo, os indicadores constituem-se em instrumentos de apoio à tomada de decisão com relação a uma determinada estrutura, processo ou produto (SOUZA e MEKBEKIAN, 1996).

\section{Princípios para elaboração dos indicadores}

Durante a elaboração dos indicadores de desempenho levaram-se em consideração alguns princípios básicos, quais sejam:

- Seletividade: não se deve elaborar um grande número de indicadores e sim selecionar os aspectos que se mostram como fatores críticos para o desempenho do sistema de gestão proposto. 
- Simplicidade: os indicadores devem ser de fácil compreensão e aplicação e, portanto, não devem estar associados a cálculos e processamentos complexos.

- Baixo custo: as despesas com a obtenção dos dados e processamento não devem ser superior ao valor do benefício que se espera obter.

- Rastreabilidade: o processo de elaboração dos indicadores deve ser detalhado o suficiente para permitir a reconstituição das etapas e resultados parciais.

- Estabilidade: o processo de elaboração dos indicadores devem se transformar numa rotina incorporada às atividades do departamento da empresa que se responsabilizará pelo sistema de gestão dos resíduos.

- Validação: os indicadores elaborados devem ser divulgados para as pessoas envolvidas no sistema de gestão, possibilitando que opinem sobre os indicadores selecionados e dando um feedback para melhoria das medidas.

Um indicador de desempenho pode ser elaborado a partir de uma ou mais variáveis. Daí poder assumir diferentes unidades de medida, podendo se apresentar como um número absoluto, uma relação de quantidade com outra referência, tempo de espera para ocorrência de um evento, percentagem de ocorrências ou custo.

\section{Formulação dos indicadores de desempenho}

Os indicadores foram agrupados conforme se relacionavam com as quatro etapas propostas para o sistema de gestão de resíduos, a saber: sensibilização, planejamento, implantação e monitoramento. Ressalta-se que a etapa de implantação da proposta está, por sua vez, dividida em qualificação dos agentes envolvidos, gestão no canteiro de obras, remoção dos resíduos do canteiro e destinação dos resíduos.

Os indicadores de desempenho formulados, e apresentados nas Tabelas 1, 2, 3 e 4, auxiliarão na avaliação do desempenho do sistema de gestão de resíduos proposto. 
Tabela 1: Indicadores de desempenho relativos à etapa de sensibilização.

\begin{tabular}{|c|c|c|c|c|}
\hline & Indicador/Fórmula & Variáveis & Unidade & Periodicidade \\
\hline & \multicolumn{4}{|l|}{ ETAPA: Sensibilização } \\
\hline 1 & $\begin{array}{l}\text { Freqüência de reuniões de } \\
\text { sensibilização } \\
\text { FRS }=\frac{\text { NRS }}{P}\end{array}$ & $\begin{array}{l}\text { NRS = número de } \\
\text { reuniões de } \\
\text { sensibilização ocorridas } \\
\mathbf{P}=\text { período (pode ser } \\
\text { mensal ou relativo ao } \\
\text { tempo total de } \\
\text { implementação do SGR) }\end{array}$ & reu/mês & $\begin{array}{l}\text { Mensal ou por } \\
\text { tempo total de } \\
\text { implementação } \\
\text { do Sistema de } \\
\text { Gestão de } \\
\text { Resíduos (SGR) }\end{array}$ \\
\hline 2 & $\begin{array}{l}\text { Índice de participação em } \\
\text { reuniões } \\
\text { IPR }=\frac{\text { NPR }}{\text { NPE }} \times 100\end{array}$ & $\begin{array}{l}\text { NPR = número de } \\
\text { pessoas participantes na } \\
\text { reunião de } \\
\text { sensibilização } \\
\text { NPE = número total de } \\
\text { pessoas que estão } \\
\text { envolvidas no SGR, } \\
\text { direta ou indiretamente } \\
\text { (equipe gerencial, } \\
\text { equipe de gestão da } \\
\text { qualidade, equipe de } \\
\text { segurança do trabalho } \\
\text { etc.) }\end{array}$ & $\%$ & $\begin{array}{l}\text { A cada reunião } \\
\text { ocorrida }\end{array}$ \\
\hline
\end{tabular}

Tabela 2: Indicadores de desempenho relativos à etapa de planejamento.

\begin{tabular}{|c|c|c|c|c|}
\hline & Indicador/Fórmula & Variáveis & Unidade & Periodicidade \\
\hline & \multicolumn{4}{|l|}{ ETAPA: Planejamento } \\
\hline 1 & $\begin{array}{l}\text { Freqüência de reuniões de } \\
\text { planejamento } \\
\text { FRP }=\frac{\text { NRP }}{\mathbf{P}}\end{array}$ & $\begin{array}{l}\text { NRP = número de } \\
\text { reuniões de } \\
\text { planejamento ocorridas } \\
\mathbf{P}=\text { período (pode ser } \\
\text { mensal ou relativo ao } \\
\text { tempo total de } \\
\text { implementação do SGR) }\end{array}$ & reu/mês & $\begin{array}{l}\text { Mensal ou por } \\
\text { tempo total de } \\
\text { implementação } \\
\text { do Sistema de } \\
\text { Gestão de } \\
\text { Resíduos (SGR) }\end{array}$ \\
\hline 2 & $\begin{array}{l}\text { Índice de eficiência do } \\
\text { planejamento } \\
\text { IEP }=\underline{\operatorname{NIE}}_{\mathbf{P}} \times 100 \\
\operatorname{NTIP}_{P}\end{array}$ & $\begin{array}{l}\text { NIE }_{\mathbf{P}}=\text { número de itens } \\
\text { do planejamento } \\
\text { executados no período } \\
\mathbf{N T I P}_{\mathbf{P}}=\text { número total } \\
\text { de itens planejados para } \\
\text { serem executados no } \\
\text { período }\end{array}$ & $\%$ & $\begin{array}{l}\text { Mensal, } \\
\text { trimestral ou } \\
\text { semestral }\end{array}$ \\
\hline
\end{tabular}


Tabela 3: Indicadores de desempenho relativos à etapa de implantação.

\begin{tabular}{|c|c|c|c|c|}
\hline & Indicador/Fórmula & Variáveis & Unidade & Periodicidade \\
\hline & \multicolumn{4}{|l|}{ ETAPA: Implantação } \\
\hline & \multicolumn{4}{|c|}{ - Qualificação dos agentes envolvidos - } \\
\hline 1 & $\begin{array}{l}\text { Índice de treinamento dos } \\
\text { operários das empresas } \\
\text { fornecedoras } \\
\text { IT }_{\mathrm{EF}}=\frac{\mathrm{NHT}}{\mathrm{NO}_{\mathrm{EF}}}\end{array}$ & $\begin{array}{l}\text { NHT }_{\text {OEF }}=\text { número de } \\
\text { horas de treinamento } \\
\text { dos operários dos } \\
\text { fornecedores de } \\
\text { dispositivos e acessórios } \\
\text { para coleta de resíduos } \\
\text { NO }_{\mathbf{E F}}=\text { número de } \\
\text { operários dos } \\
\text { fornecedores }\end{array}$ & h/oper & $\begin{array}{l}\text { Mensal ou por } \\
\text { tempo total de } \\
\text { implementação } \\
\text { do Sistema de } \\
\text { Gestão de } \\
\text { Resíduos (SGR) }\end{array}$ \\
\hline 2 & $\begin{array}{l}\text { Índice de treinamento dos } \\
\text { operários das empresas } \\
\text { coletoras } \\
\mathrm{IT}_{\mathrm{EC}}=\frac{\mathrm{NHT}_{\mathrm{OEC}}}{\mathrm{NO}_{\mathrm{EC}}}\end{array}$ & $\begin{array}{l}\text { NHT }_{\text {OEC }}=\text { número de } \\
\text { horas de treinamento } \\
\text { dos operários das } \\
\text { empresas coletoras } \\
\text { NO }_{\text {EC }}=\text { número de } \\
\text { operários das empresas } \\
\text { coletoras }\end{array}$ & h/oper & $\begin{array}{l}\text { Mensal ou por } \\
\text { tempo total de } \\
\text { implementação } \\
\text { do Sistema de } \\
\text { Gestão de } \\
\text { Resíduos (SGR) }\end{array}$ \\
\hline 3 & $\begin{array}{l}\text { Índice de treinamento dos } \\
\text { operários da obra } \\
\mathrm{IT}_{\mathrm{O}}=\frac{\mathrm{NHT}_{\mathrm{OO}}}{\mathrm{NO}_{\mathrm{O}}}\end{array}$ & $\begin{array}{l}\text { NHT }_{\mathbf{o o}}=\text { número de } \\
\text { horas de treinamento } \\
\text { dos operários da obra } \\
\text { NO}_{\mathbf{o}}=\text { número de } \\
\text { operários da obra }\end{array}$ & h/oper & $\begin{array}{l}\text { Mensal ou por } \\
\text { tempo total de } \\
\text { implementação } \\
\text { do Sistema de } \\
\text { Gestão de } \\
\text { Resíduos (SGR) }\end{array}$ \\
\hline 4 & $\begin{array}{l}\text { Índice de treinamento dos } \\
\text { operários das áreas de } \\
\text { disposição dos resíduos } \\
\mathrm{IT}_{\mathrm{AD}}=\frac{\mathrm{NHT}_{\mathrm{OAD}}}{\mathrm{NO}_{\mathrm{AD}}}\end{array}$ & $\begin{array}{l}\text { NHT }_{\mathbf{O A D}}=\text { número de } \\
\text { horas de treinamento } \\
\text { dos operários que } \\
\text { trabalham nas áreas de } \\
\text { disposição dos resíduos } \text { NO }_{\text {AD }}=\text { número de } \\
\text { operários das áreas de } \\
\text { disposição dos resíduos }\end{array}$ & h/oper & $\begin{array}{l}\text { Mensal ou por } \\
\text { tempo total de } \\
\text { implementação } \\
\text { do Sistema de } \\
\text { Gestão de } \\
\text { Resíduos (SGR) }\end{array}$ \\
\hline
\end{tabular}


Tabela 3: Indicadores de desempenho relativos à etapa de implantação (cont.).

\begin{tabular}{|c|c|c|c|c|}
\hline & Indicador/Fórmula & Variáveis & Unidade & Periodicidade \\
\hline & \multicolumn{4}{|l|}{ ETAPA: Implantação (cont.) } \\
\hline & \multicolumn{4}{|c|}{ - Gestão no canteiro de obras - } \\
\hline 1 & $\begin{array}{l}\text { Índice de utilização de } \\
\text { dispositivos e acessórios } \\
\text { para coleta } \\
\text { IUDC }=\frac{\text { NDAU }}{\text { NPA }}\end{array}$ & $\begin{array}{l}\text { NDAU = número de } \\
\text { dispositivos e acessórios } \\
\text { utilizados } \\
\text { NPA = número de } \\
\text { pavimentos da obra }\end{array}$ & un/pav & $\begin{array}{l}\text { Mensal ou por } \\
\text { tempo total de } \\
\text { implementação } \\
\text { do Sistema de } \\
\text { Gestão de } \\
\text { Resíduos (SGR) }\end{array}$ \\
\hline 2 & $\begin{array}{l}\text { Índice de reaproveitamento } \\
\text { de material } \\
\text { IReM }=\frac{\text { VMRe }}{\text { VTR }} 100\end{array}$ & $\begin{array}{l}\text { VMRe = volume total } \\
\text { de material } \\
\text { reaproveitado } \\
\text { VTR = volume total de } \\
\text { resíduos gerados no } \\
\text { período }\end{array}$ & $\%$ & $\begin{array}{l}\text { Mensal, } \\
\text { trimestral ou } \\
\text { semestral }\end{array}$ \\
\hline 3 & $\begin{array}{l}\text { Índice de limpeza dos } \\
\text { resíduos } \\
\text { ILR }=\frac{\text { NLR }}{\text { NPA }}\end{array}$ & $\begin{array}{l}\text { NLR = número de locais } \\
\text { de deposição de resíduos } \\
\text { no canteiro } \\
\text { NPA = número de } \\
\text { pavimentos da obra }\end{array}$ & un/pav & $\begin{array}{l}\text { Mensal, } \\
\text { trimestral ou } \\
\text { semestral }\end{array}$ \\
\hline 4 & $\begin{array}{l}\text { Índice de eficiência do fluxo } \\
\text { dos resíduos } \\
\text { IEF }=\left(1-\frac{\text { NNC }}{\text { NTF }} \times 100\right.\end{array}$ & $\begin{array}{l}\text { NNC = número de não } \\
\text { conformidades } \\
\text { existentes no fluxo de } \\
\text { resíduos } \\
\text { NTF = número de } \\
\text { fluxos ocorridos no } \\
\text { período }\end{array}$ & $\%$ & $\begin{array}{l}\text { Mensal, } \\
\text { trimestral ou } \\
\text { semestral }\end{array}$ \\
\hline 5 & $\begin{array}{l}\text { Índice de formalização de } \\
\text { procedimentos } \\
\text { IFP }=\frac{\text { NPF }}{\text { NTP }} 100\end{array}$ & $\begin{array}{l}\text { NPF = número de } \\
\text { procedimentos } \\
\text { formalizados } \\
\mathbf{N T P}=\text { número total de } \\
\text { procedimentos previstos }\end{array}$ & $\%$ & $\begin{array}{l}\text { Mensal, } \\
\text { trimestral ou } \\
\text { semestral }\end{array}$ \\
\hline 6 & $\begin{array}{l}\text { Índice de atendimento às } \\
\text { disposições legais existentes, } \\
\text { quanto ao manuseio e } \\
\text { disposição dos resíduos no } \\
\text { canteiro } \\
\text { IAD }_{C}=\left(1-\frac{\mathrm{NA})}{\mathrm{NTD}} \times 100\right. \\
\qquad\end{array}$ & $\begin{array}{l}\text { NA = número de } \\
\text { autuações, internas e } \\
\text { externas, ocorridas no } \\
\text { período } \\
\text { NTD }_{\mathbf{C}}=\text { número total de } \\
\text { disposições a serem } \\
\text { cumpridas }\end{array}$ & $\%$ & $\begin{array}{l}\text { Mensal, } \\
\text { trimestral ou } \\
\text { semestral }\end{array}$ \\
\hline
\end{tabular}


Tabela 3: Indicadores de desempenho relativos à etapa de implantação (cont.).

\begin{tabular}{|c|c|c|c|}
\hline Indicador/Fórmula & Variáveis & Unidade & Periodicidade \\
\hline
\end{tabular}

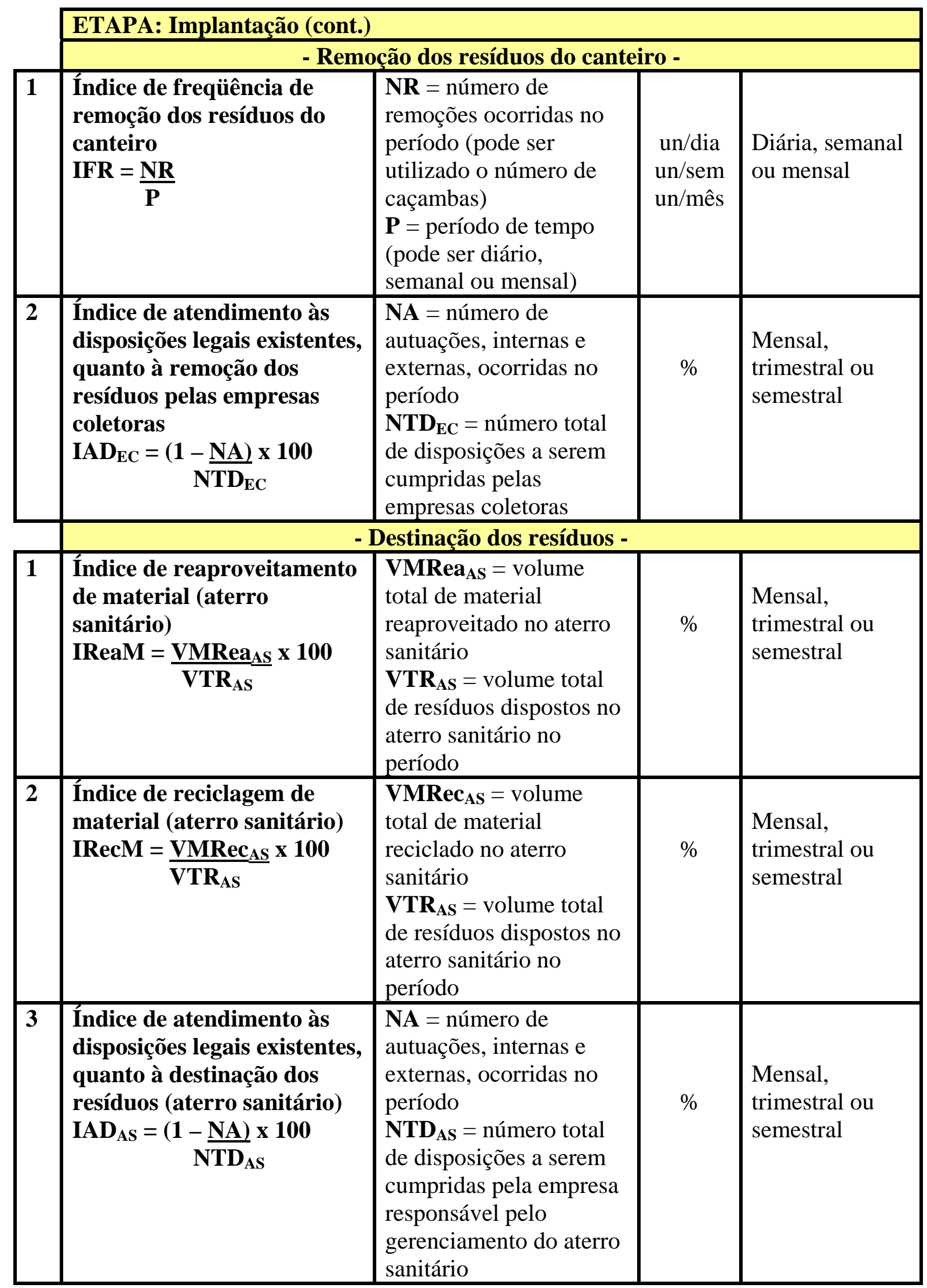


Tabela 4: Indicadores de desempenho relativos à etapa de monitoramento.

\begin{tabular}{|l|l|l|l|}
\hline Indicador/Fórmula & Variáveis & Unidade & Periodicidade \\
\hline
\end{tabular}

\begin{tabular}{|c|c|c|c|c|}
\hline & \multicolumn{4}{|l|}{ ETAPA: Monitoramento } \\
\hline 1 & $\begin{array}{l}\text { Índice de aplicação de } \\
\text { check-lists } \\
\text { IAC }=\frac{\text { NCA }}{\text { NTC }} \times 100\end{array}$ & $\begin{array}{l}\text { NCA }=n^{0} \text { de check-lists } \\
\text { aplicados no período } \\
\text { NTC }=n^{0} \text { total de } \\
\text { check-lists elaborados } \\
\text { para monitoramento das } \\
\text { ações implementadas }\end{array}$ & $\%$ & $\begin{array}{l}\text { Mensal, } \\
\text { trimestral ou } \\
\text { semestral }\end{array}$ \\
\hline 2 & $\begin{array}{l}\text { Índice de relatórios } \\
\text { emitidos } \\
\text { IRE }=\frac{\text { NRE }}{\mathbf{P}}\end{array}$ & $\begin{array}{l}\text { NRE = no de relatórios } \\
\text { emitidos no período } \\
\text { para acompanhar as } \\
\text { ações de gestão } \\
\text { implementadas } \\
\mathbf{P}=\text { período de tempo } \\
\text { (pode ser semanal, } \\
\text { mensal ou semestral) } \\
\end{array}$ & $\begin{array}{l}\mathrm{rel} / \mathrm{sem} \\
\mathrm{rel} / \mathrm{mês} \\
\text { res/ } \\
\text { semestre }\end{array}$ & $\begin{array}{l}\text { Semanal, } \\
\text { mensal ou } \\
\text { semestral }\end{array}$ \\
\hline 3 & $\begin{array}{l}\text { Índice de deposição final } \\
\text { dos resíduos } \\
\text { IDF }=\frac{\text { VRO }}{\text { VRF }}\end{array}$ & $\begin{array}{l}\text { VRO = volume de } \\
\text { resíduos que } \\
\text { efetivamente sai da obra } \\
\text { no período } \\
\text { VRF = volume de } \\
\text { resíduos dispostos no } \\
\text { aterro sanitário no } \\
\text { período }\end{array}$ & $\%$ & $\begin{array}{l}\text { Mensal, } \\
\text { trimestral ou } \\
\text { semestral }\end{array}$ \\
\hline 4 & $\begin{array}{l}\text { Custo financeiro com coleta } \\
\text { e remoção dos resíduos do } \\
\text { canteiro } \\
\mathrm{CF}_{\mathrm{CR}}=\frac{\mathrm{CTF}}{\mathrm{P}} \frac{\mathrm{CR}}{}\end{array}$ & $\begin{array}{l}\mathbf{C T F}_{\mathbf{C R}}=\text { custo total } \\
\text { financeiro da obra ou } \\
\text { empresa com coleta e } \\
\text { remoção de resíduos } \\
\mathbf{P}=\text { período de tempo } \\
\text { (pode ser semanal, } \\
\text { mensal ou semestral) }\end{array}$ & $\begin{array}{c}\mathrm{R} \$ / \text { sem } \\
\mathrm{R} \$ / \mathrm{mês} \\
\mathrm{R} \$ / \\
\text { semestre }\end{array}$ & $\begin{array}{l}\text { Semanal, } \\
\text { mensal ou } \\
\text { semestral }\end{array}$ \\
\hline 5 & $\begin{array}{l}\text { Custo financeiro relativo } \\
\text { com coleta e remoção dos } \\
\text { resíduos do canteiro } \\
\mathrm{CF}_{\mathrm{R}}=\frac{\mathrm{CTF}}{\mathrm{CTF}_{\mathrm{AA}}}\end{array}$ & $\begin{array}{l}\mathbf{C T F}_{\mathbf{C R}}=\text { custo total } \\
\text { financeiro da obra ou } \\
\text { empresa com deposição, } \\
\text { coleta e remoção de } \\
\text { resíduos } \\
\text { CTF }_{\text {AA }}=\text { custo total } \\
\text { financeiro da obra ou } \\
\text { empresa com deposição, } \\
\text { coleta e remoção de } \\
\text { resíduos no ano anterior }\end{array}$ & $\%$ & Anual \\
\hline
\end{tabular}




\section{MODELO PARA AVALIAÇÃO DO DESEMPENHO DO SISTEMA}

A partir dos indicadores de desempenho formulados, anteriormente, sugere-se um modelo para avaliação do desempenho do sistema de gestão de resíduos a ser implantado. A configuração desse modelo toma como base, mais uma vez, as quatro etapas do sistema proposto e suas respectivas subdivisões.

Os pesos atribuídos a cada indicador do modelo foram resultantes de uma análise minuciosa por parte dos autores, levando em consideração o bom senso. Ressalta-se, no entanto, que os mesmos não deixam de ter o caráter subjetivo e, portanto, não devem ser tomados como definitivos. Sugere-se, inclusive, que os pesos sejam analisados e revisados periodicamente pelas empresas que venham a fazer uso do sistema, em função de adequações a suas próprias realidades e de alterações conjunturais.

No modelo proposto foram estabelecidos os critérios para identificação das pontuações. Esses critérios servem para determinar as pontuações a partir dos valores calculados para cada indicador, conforme as Tabelas 1, 2, 3 e 4, mostradas anteriormente.

Determinadas as pontuações, segue-se com o cálculo das notas de cada um dos indicadores, que é o resultado da multiplicação dos pesos pelas respectivas pontuações.

Como forma de melhor visualizar esses cálculos pode-se tomar como exemplo um indicador: freqüência de reuniões de sensibilização (indicador 1 da Tabela 1). Ao calcular o valor do indicador para uma empresa hipotética, obteve-se como resultado 3 reuniões mensais. Considerando os critérios (Tabela 5), tem-se 2 pontos. Assim, ao se multiplicar o peso (5) pela pontuação (2) obtém-se, então, a nota 10.

Para se ter uma visão geral das notas obtidas, realiza-se o somatório das mesmas e posteriormente o cálculo da nota final de cada uma das quatro etapas, que consiste na multiplicação entre o somatório das notas e o valor de 0,25 , valor este que representa uma dentre quatro etapas que fazem parte do modelo.

Todos esses detalhes do modelo podem ser vistos nas Tabelas 5, 6, 7 e 8.

Tabela 5: Modelo relativo à etapa de sensibilização.

\begin{tabular}{|c|c|c|c|c|}
\hline Indicador & Peso & $\begin{array}{c}\text { Critérios para } \\
\text { determinação das } \\
\text { pontuações }\end{array}$ & Pontuação & Nota \\
\hline
\end{tabular}

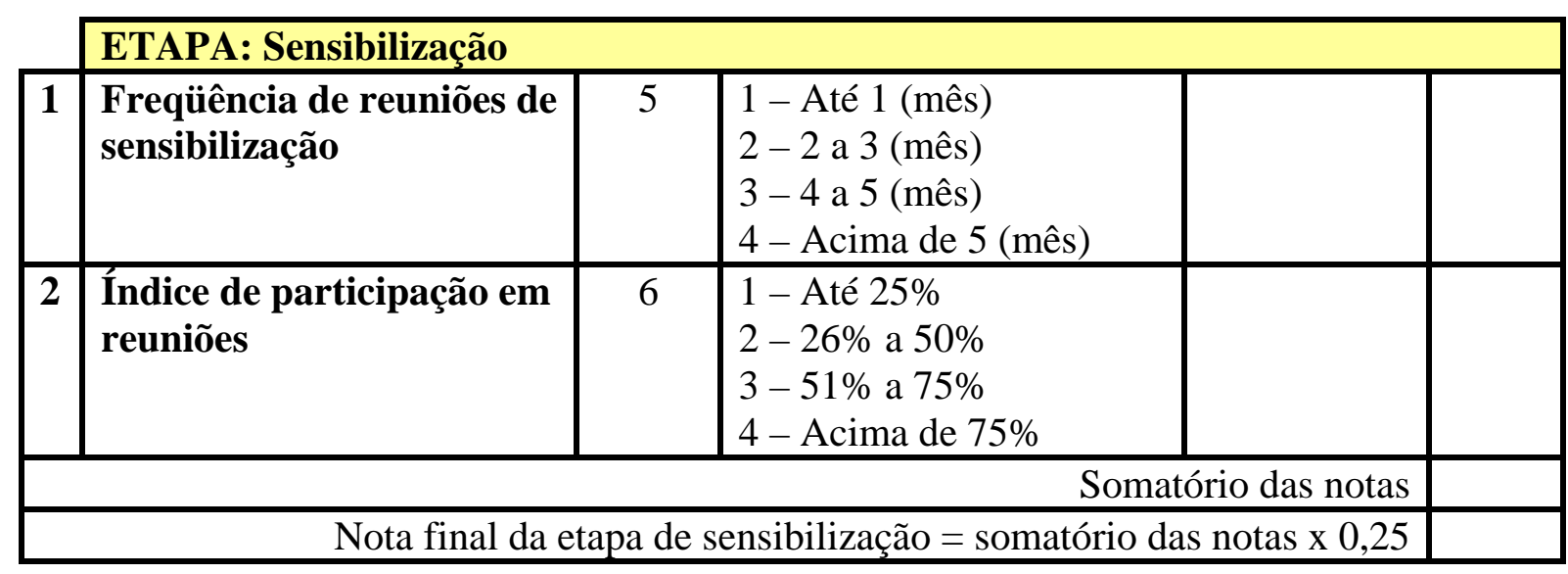


Tabela 6: Modelo relativo à etapa de planejamento.

\begin{tabular}{|c|c|c|c|c|}
\hline Indicador & Peso & $\begin{array}{c}\text { Critérios para } \\
\text { determinação das } \\
\text { pontuações }\end{array}$ & Pontuação & Nota \\
\hline
\end{tabular}

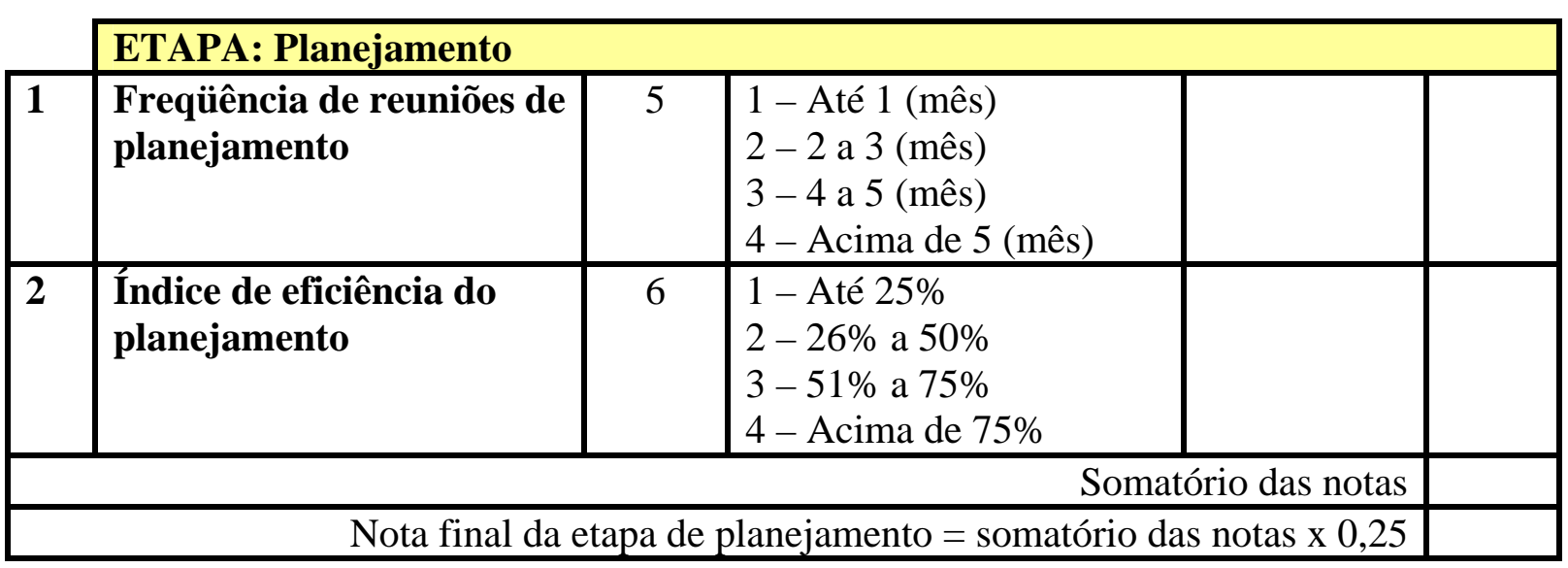

Tabela 7: Modelo relativo à etapa de implantação.

\begin{tabular}{|c|c|c|c|c|}
\hline Indicador & Peso & $\begin{array}{c}\text { Critérios para } \\
\text { determinação das } \\
\text { pontuações }\end{array}$ & Pontuação & Nota \\
\hline
\end{tabular}

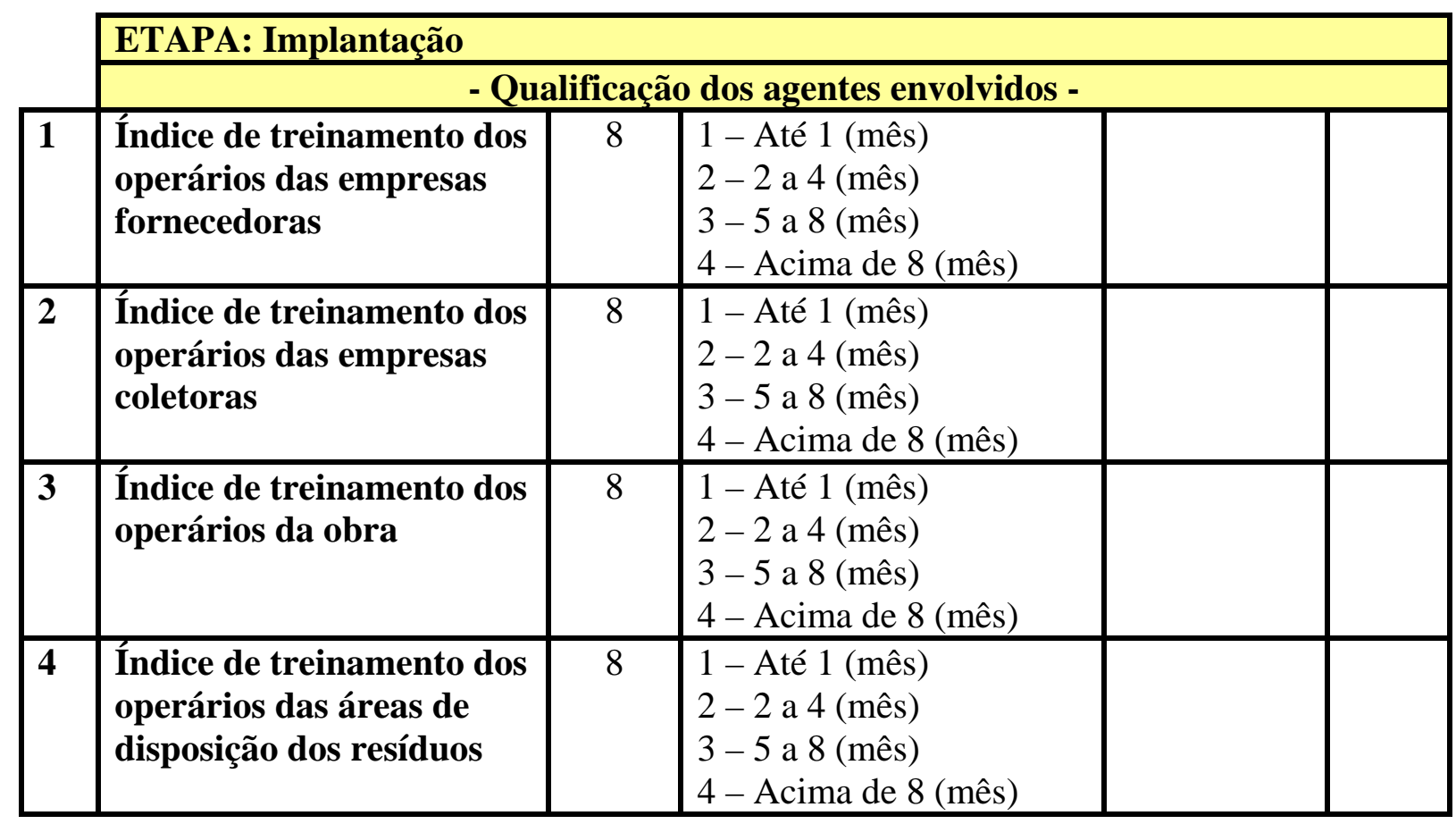


Tabela 7: Modelo relativo à etapa de implantação (cont.).

\begin{tabular}{|c|c|c|c|c|c|}
\hline & Indicador & Peso & $\begin{array}{c}\text { Critérios para } \\
\text { determinação das } \\
\text { pontuações }\end{array}$ & Pontuação & Nota \\
\hline & \multicolumn{5}{|c|}{ - Gestão no canteiro de obras - } \\
\hline 1 & $\begin{array}{l}\text { Índice de utilização de } \\
\text { dispositivos e acessórios } \\
\text { para coleta }\end{array}$ & 4 & $\begin{array}{l}1 \text { - Menos de } 1 \text { (unidade) } \\
2-1 \text { a } 2 \text { (unidades) } \\
3 \text { - } 3 \text { a } 4 \text { (unidades) } \\
4 \text { - Acima de } 4 \text { (unidades) }\end{array}$ & & \\
\hline 2 & $\begin{array}{l}\text { Índice de } \\
\text { reaproveitamento de } \\
\text { material }\end{array}$ & 9 & $\begin{array}{l}1 \text { - Até } 25 \% \\
2-26 \% \text { a } 50 \% \\
3-51 \% \text { a } 75 \% \\
4 \text { - Acima de } 75 \%\end{array}$ & & \\
\hline 3 & $\begin{array}{l}\text { Índice de limpeza dos } \\
\text { resíduos }\end{array}$ & 6 & $\begin{array}{l}1 \text { - Abaixo de } 0,5 \\
\text { (unidades) } \\
2-0,5 \text { a } 0,9 \text { (unidades) } \\
3-1 \text { a } 2 \text { (unidades) } \\
4 \text { - Acima de } 2 \text { (unidades) }\end{array}$ & & \\
\hline 4 & $\begin{array}{l}\text { Índice de eficiência do } \\
\text { fluxo dos resíduos }\end{array}$ & 5 & $\begin{array}{l}1 \text { - Até } 25 \% \\
2-26 \% \text { a } 50 \% \\
3-51 \% \text { a } 75 \% \\
4 \text { - Acima de } 75 \% \\
\end{array}$ & & \\
\hline 5 & $\begin{array}{l}\text { Índice de formalização de } \\
\text { procedimentos }\end{array}$ & 4 & $\begin{array}{l}1-\text { Até } 25 \% \\
2-26 \% \text { a } 50 \% \\
3-51 \% \text { a } 75 \% \\
4 \text { - Acima de } 75 \% \\
\end{array}$ & & \\
\hline \multirow[t]{2}{*}{6} & $\begin{array}{l}\text { Índice de atendimento às } \\
\text { disposições legais } \\
\text { existentes, quanto ao } \\
\text { manuseio e disposição dos } \\
\text { resíduos no canteiro }\end{array}$ & 7 & $\begin{array}{l}1 \text { - Até } 25 \% \\
2-26 \% \text { a } 50 \% \\
3-51 \% \text { a } 75 \% \\
4 \text { - Acima de } 75 \%\end{array}$ & & \\
\hline & \multicolumn{5}{|c|}{ - Remoção dos resíduos do canteiro - } \\
\hline 1 & $\begin{array}{l}\text { Índice de freqüência de } \\
\text { remoção dos resíduos do } \\
\text { canteiro }\end{array}$ & 5 & $\begin{array}{l}1 \text { - Acima de } 5 \text { (semana) } \\
2 \text { - } 4 \text { a } 5 \text { (semana) } \\
3 \text { - } 2 \text { a } 3 \text { (semana) } \\
4 \text { - Até } 1 \text { (semana) }\end{array}$ & & \\
\hline 2 & $\begin{array}{l}\text { Índice de atendimento às } \\
\text { disposições legais } \\
\text { existentes, quanto à } \\
\text { remoção dos resíduos } \\
\text { pelas empresas coletoras }\end{array}$ & 7 & $\begin{array}{l}1-\text { Até } 25 \% \\
2-26 \% \text { a } 50 \% \\
3-51 \% \text { a } 75 \% \\
4 \text { - Acima de } 75 \%\end{array}$ & & \\
\hline
\end{tabular}


Tabela 7: Modelo relativo à etapa de implantação (cont.).

\begin{tabular}{|c|c|c|c|c|}
\hline Indicador & Peso & $\begin{array}{c}\text { Critérios para } \\
\text { determinação das } \\
\text { pontuações }\end{array}$ & Pontuação & Nota \\
\hline
\end{tabular}

\begin{tabular}{|c|c|c|c|c|}
\hline & \multicolumn{4}{|c|}{ - Destinação dos resíduos - } \\
\hline $\mathbf{1}$ & $\begin{array}{l}\text { Índice de } \\
\text { reaproveitamento de } \\
\text { material (aterro } \\
\text { sanitário) }\end{array}$ & 8 & $\begin{array}{l}1-\text { Até } 25 \% \\
2-26 \% \text { a } 50 \% \\
3-51 \% \text { a } 75 \% \\
4 \text { - Acima de } 75 \%\end{array}$ & \\
\hline 2 & $\begin{array}{l}\text { Índice de reciclagem de } \\
\text { material (aterro } \\
\text { sanitário) }\end{array}$ & 8 & $\begin{array}{l}1 \text { - Até } 25 \% \\
2-26 \% \text { a } 50 \% \\
3-51 \% \text { a } 75 \% \\
4 \text { - Acima de } 75 \%\end{array}$ & \\
\hline 3 & $\begin{array}{l}\text { Índice de atendimento } \\
\text { às disposições legais } \\
\text { existentes, quanto à } \\
\text { destinação dos resíduos } \\
\text { (aterro sanitário) }\end{array}$ & 7 & $\begin{array}{l}1-\text { Até } 25 \% \\
2-26 \% \text { a } 50 \% \\
3-51 \% \text { a } 75 \% \\
4-\text { Acima de } 75 \%\end{array}$ & \\
\hline \multicolumn{5}{|c|}{ Somatório das notas } \\
\hline \multicolumn{5}{|c|}{ Nota final da etapa de implantação = somatório das notas x 0,25} \\
\hline
\end{tabular}


Tabela 8: Modelo relativo à etapa de monitoramento.

\begin{tabular}{|c|c|c|c|c|}
\hline Indicador & Peso & $\begin{array}{c}\text { Critérios para } \\
\text { determinação das } \\
\text { pontuações }\end{array}$ & Pontuação & Nota \\
\hline
\end{tabular}

\begin{tabular}{|c|c|c|c|c|c|}
\hline & ETAPA: Monitoramento & & & & \\
\hline 1 & $\begin{array}{l}\text { Índice de aplicação de } \\
\text { check-lists }\end{array}$ & 3 & $\begin{array}{l}1 \text { - Até } 25 \% \\
2-26 \% \text { a } 50 \% \\
3-51 \% \text { a } 75 \% \\
4-\text { Acima de } 75 \%\end{array}$ & & \\
\hline 2 & $\begin{array}{l}\text { Índice de relatórios } \\
\text { emitidos }\end{array}$ & 4 & $\begin{array}{l}1 \text { - Até } 1 \text { (mês) } \\
2 \text { - } 2 \text { a } 3 \text { (mês) } \\
3 \text { - } 4 \text { a } 5 \text { (mês) } \\
4 \text { - Acima de } 5 \text { (mês) }\end{array}$ & & \\
\hline 3 & $\begin{array}{l}\text { Índice de deposição final } \\
\text { dos resíduos }\end{array}$ & 6 & $\begin{array}{l}1-\text { Até } 25 \% \\
2-26 \% \text { a } 50 \% \\
3-51 \% \text { a } 75 \% \\
4 \text { - Acima de } 75 \% \\
\end{array}$ & & \\
\hline 4 & $\begin{array}{l}\text { Custo financeiro com } \\
\text { coleta e remoção dos } \\
\text { resíduos do canteiro }\end{array}$ & 7 & $\begin{array}{l}1 \text { - Acima de } \mathrm{R} \$ 175,00 \\
\text { (semana) } \\
\text { 2- Entre } \mathrm{R} \$ 140,00 \text { e } \\
\mathrm{R} \$ 175,00 \text { (semana) } \\
3 \text { - Entre } \mathrm{R} \$ 70,00 \text { e } \\
\mathrm{R} \$ 105,00 \text { (semana) } \\
4 \text { - Até } \mathrm{R} \$ 35,00 \\
\text { (semana) }^{1}\end{array}$ & & \\
\hline 5 & $\begin{array}{l}\text { Custo financeiro relativo } \\
\text { com coleta e remoção dos } \\
\text { resíduos do canteiro }\end{array}$ & 7 & $\begin{array}{l}1-\text { Até } 25 \% \\
2-26 \% \text { a } 50 \% \\
3-51 \% \text { a } 75 \% \\
4 \text { - Acima de } 75 \%\end{array}$ & & \\
\hline \multicolumn{5}{|c|}{ Somatório das notas } & \\
\hline \multicolumn{5}{|c|}{ Nota final da etapa de monitoramento $=$ somatório das notas $\times$ 0,25} & \\
\hline
\end{tabular}

Ao final, ao calcular as notas para cada uma das quatro etapas, prossegue-se com o cálculo da nota final geral, correspondente a todas as etapas juntas, como visto a seguir.

\section{NOTA FINAL GERAL}

[nota final da etapa de sensibilização (tabela 5) + nota final da etapa de planejamento (tabela 6) + nota final da etapa de implantação (tabela 7) + nota final da etapa de monitoramento (tabela 8] / 4

\footnotetext{
${ }^{1}$ Valores de referência para a Cidade de João Pessoa em caçamba de 4,5m³ (fevereiro de 2007).
} 


\section{CONSIDERAÇÕES FINAIS}

O Sistema de Gestão de Resíduos Sólidos preconizado pela Resolução $n^{\circ} 307$ do CONAMA ainda não foi implementado na cidade de João Pessoa, pelo órgão competente (EMLUR). Entretanto, já existem estudos com a elaboração das diretrizes para sua implantação e, no presente artigo, propõe-se uma maneira de monitoramento deste Sistema de Gestão, através de um modelo que contempla diversos indicadores de desempenho.

Os indicadores foram elaborados conforme as etapas propostas no Sistema de Gestão e obedecendo a diversos princípios, a exemplo de simplicidade e baixo custo. Entretanto, para se obter êxito no monitoramento através do modelo, é necessário que todas as etapas da proposta de gestão tenham sido implementadas. Caso contrário haverá dificuldade na coleta dos dados, fugindo-se dessa forma ao princípio da simplicidade e a outros elencados no trabalho.

O modelo e conseqüentemente seus indicadores de desempenho propostos servirão de referência na avaliação do desempenho do Sistema de Gestão de Resíduos e a partir daí será possível a tomada de decisões com base em dados reais e mensuráveis, quer seja para o caso da cidade de João Pessoa, alvo do presente estudo, quer seja para qualquer outra localidade, desde que adaptado as suas características particulares.

De uma forma geral, acredita-se que não apenas a implantação, mas também o monitoramento do Sistema de Gestão de Resíduos Sólidos nas construtoras, trarão inúmeros ganhos para as construtoras, para a sociedade e para o meio ambiente.

\section{REFERÊNCIAS BIBLIOGRÁFICAS}

1. ARAÚJO, N. M. C.; et al. Empresas construtoras pessoenses x resolução $\mathrm{n}^{0} 307$ do CONAMA: pontos positivos e negativos. In: SIMPÓSIO BRASILEIRO DE GESTÃO E ECONOMIA DA CONSTRUÇÃO, 4., 2005, Porto Alegre. Anais...Porto Alegre: UFRGS, 2005a. 1 CD.

2. ARAÚJO, N. M. C.; et al. Proposta de gestão para os resíduos de construção e demolição (RCD) da grande João Pessoa. In: SIMPÓSIO BRASILEIRO DE GESTÃO E ECONOMIA DA CONSTRUÇÃO, 4., 2005, Porto Alegre. Anais...Porto Alegre: UFRGS, 2005b. 1 CD.

3. BRASIL. Resolução CONAMA n ${ }^{0}$. 307, de 5 de julho de 2002. Estabelece diretrizes, critérios e procedimentos para a gestão dos resíduos da construção civil. Diário Oficial da União, Brasília, DF, 17 de julho de 2002.

4. MONTEIRO, J. H. P.; et al. Manual de gerenciamento integrado de resíduos sólidos. Rio de Janeiro: IBAM, 2001.

5. PINTO, T. P. Gestão ambiental de resíduos da construção civil: a experiência do SindusCon-SP. São Paulo: Obra Limpa: I \& T: SindusCon-SP, 2005.

6. SOUZA, R.; MEKBEKIAN, G. Qualidade na aquisição de materiais e execução de obras. São Paulo: Pini, 1996. 